\title{
Parabacteroides chartae sp. nov., an obligately anaerobic species from wastewater of a paper mill
}

\author{
Hai-Oin Tan, Tian-Tian Li, Chu Zhu, Xin-Qi Zhang, Min Wu \\ and $\mathrm{Xu}$-Fen Zhu \\ College of Life Sciences, Zhejiang University, 866 Yuhangtang Road, Hangzhou, \\ Zhejiang Province 310058, PR China
}

Correspondence

Xu-Fen Zhu

xufenzhu@zju.edu.cn

\begin{abstract}
A bacterial strain, designated NS31-3 ${ }^{\top}$, was isolated from the wastewater of a paper mill. Cells of the isolate were obligately anaerobic, non-pigmented, non-motile, Gram-negative, short rods $(0.7-1.0 \times 1.4-2.5 \mu \mathrm{m})$. The isolate was able to grow on media containing $20 \%$ bile salts. API $20 \mathrm{~A}$ tests showed that acid was produced from glucose, lactose, sucrose, maltose, D-xylose, Larabinose, cellobiose, D-mannose, D-melezitose, D-raffinose, D-trehalose, D-mannitol, salicin and D-sorbitol. The main fermentation products from PYG broth were lactic acid, propionic acid, formic acid and acetic acid. Chemotaxonomic analysis showed that the major fatty acids were anteiso- $\mathrm{C}_{15: 0}, \mathrm{C}_{15 \text { : } 0}$ and iso- $\mathrm{C}_{17: 0} 3-\mathrm{OH}$ and the predominant respiratory quinones were MK-9 and MK-10. Phylogenetic analysis based on 16S rRNA gene sequences showed that strain NS31- $3^{\top}$ was related to members of genus Parabacteroides (91.2-93.2\% sequence similarity); the isolate had the closest affinity with Parabacteroides merdae JCM $9497^{\top}$. The $\mathrm{G}+\mathrm{C}$ content of the genomic DNA was $37.2 \mathrm{~mol} \%$. On the basis of phenotypic, chemotaxonomic and phylogenetic analysis, strain NS31-3 ${ }^{\top}$ represents a novel species of the genus Parabacteroides, for which the name Parabacteroides chartae sp. nov. is proposed. The type strain is NS31- $3^{\top}$ $\left(=\mathrm{JCM} 17797^{\top}=\right.$ DSM $\left.24967^{\top}\right)$.
\end{abstract}

On the basis of phylogenetic distinction and menaquinone composition, it was proposed that three species of the genus Bacteroides, Bacteroides distasonis (Eggerth \& Gagnon, 1933), B. goldsteinii (Song et al., 2005) and B. merdae (Johnson et al., 1986), did not belong to the genus Bacteroides and thus were reclassified as members of a new genus, Parabacteroides, by Sakamoto \& Benno (2006). Subsequently, another two species, Parabacteroides johnsonii and Parabacteroides gordonii, were proposed by Sakamoto et al. (2007, 2009). Members of this genus are characteristically obligately anaerobic, Gram-negative, non-spore-forming, non-motile rods and can grow on media containing $20 \%$ bile salts. Metabolically, members of the genus are saccharolytic and produce acetic acid and succinic acid as the major end-products of fermentation. In terms of chemotaxonomic properties, the major respiratory quinones are MK-9 and $\mathrm{MK}-10$ and the major fatty acids are non-hydroxylated and 3-hydroxylated longchain acids (Sakamoto \& Benno, 2006). Most species of the genus Parabacteroides have been isolated from human faeces and clinical specimens (Song et al., 2005; Simmon et al., 2008).

The GenBank/EMBL/DDBJ accession number for the $16 \mathrm{~S}$ rRNA gene sequence of strain NS31-3 ${ }^{\top}$ is JN029805.

A supplementary figure is available with the online version of this paper.
An obligately anaerobic bacterium was isolated from the wastewater of a paper mill in Lingqiao town $\left(30^{\circ} 15^{\prime} \mathrm{N}\right.$ $\left.120^{\circ} 10^{\prime} \mathrm{E}\right)$, Zhejiang Province, China, in May 2010. The initial enrichment used medium Gs [containing $1^{-1}$ distilled water: $10 \mathrm{~g} \mathrm{NaCl}, 1.0 \mathrm{~g} \mathrm{MgCl}_{2} \cdot 6 \mathrm{H}_{2} \mathrm{O}, 0.5 \mathrm{~g}$ $\mathrm{K}_{2} \mathrm{HPO}_{4}, 0.7 \mathrm{~g} \quad \mathrm{KH}_{2} \mathrm{PO}_{4}, 0.025 \mathrm{~g} \quad \mathrm{FeSO}_{4} .7 \mathrm{H}_{2} \mathrm{O}, 0.2 \mathrm{~g}$ $\mathrm{CaCl}_{2} \cdot 2 \mathrm{H}_{2} \mathrm{O}, 1.0 \mathrm{~g}$ urea, $5 \mathrm{~g}$ yeast extract (Difco), $5 \mathrm{~g}$ tryptone, $1 \mathrm{ml}$ trace element solution SL-10 (Widdel et al., 1983), $0.4 \mathrm{~g}$ L-cysteine and $0.001 \mathrm{~g}$ resazurin]. The Hungate roll-tube technique (Hungate, 1969; Bryant, 1972) was used to isolate strains from the turbid enrichment cultures. After 2 days of incubation at $37{ }^{\circ} \mathrm{C}$ under a gas phase of $\mathrm{O}_{2}$-free $\mathrm{N}_{2}$, an off-white-grey colony, designated NS31-3 ${ }^{\mathrm{T}}$, was picked from Gs agar. The isolate was purified by repeated subcultivation and was preserved in $25 \%$ glycerol at $-80{ }^{\circ} \mathrm{C}$. Medium Gs supplemented with $1 \%$ beef extract (medium Gss) was used to maintain the isolate and two reference strains, Parabacteroides distasonis JCM 5825 ${ }^{\mathrm{T}}$ and Parabacteroides merdae JCM $9497^{\mathrm{T}}$.

Cell motility and morphology were examined using light microscopy (BX40; Olympus) and transmission electron microscopy (JEM-1230; JEOL) during the late-exponential phase. Growth at $\mathrm{pH}$ 5.0-10.0 was determined by adjusting the medium with the following buffers $(25 \mathrm{mM})$ : MES ( $\mathrm{pH}$ 5.0-6.0), PIPES ( $\mathrm{pH}$ 6.5-7.0), Tricine ( $\mathrm{pH}$ 7.5-8.5) and CAPSO ( $\mathrm{pH} 9.0-10.0)$. Conditions for growth were 
also determined at $4,10,16,22,28,32,37,40$ and $45{ }^{\circ} \mathrm{C}$ and with $0-6 \%(\mathrm{w} / \mathrm{v}) \mathrm{NaCl}$ (in increments of $0.5 \%$ ). Bacteroides bile salts aesculin medium (Shah, 1992) was used to check whether bile salts inhibited growth of the isolate. Physiological and biochemical reactions were determined in duplicate using the API 20A anaerobe test kit and the API ZYM test kit (bioMérieux), according to the manufacturer's instructions. Catalase and urease, as well as hydrolysis of gelatin and aesculin, were examined using standard approaches (Gerhardt et al., 1994). The end-products of fermentation were determined after growth in PYG broth ( $1 \%$ peptone, $1 \%$ yeast extract, $1 \%$ glucose).

Fatty acid methyl esters of strain NS31-3 ${ }^{\mathrm{T}}$, P. distasonis JCM $5825^{\mathrm{T}}$ and P. merdae JCM $9497^{\mathrm{T}}$ were obtained from cells grown to late-exponential phase in medium Gss at
$37{ }^{\circ} \mathrm{C}$ for $24 \mathrm{~h}$ and then freeze dried, as described by Kuykendall et al. (1988). The identification and quantification of the fatty acid methyl esters as well as the numerical analysis of the fatty acids were examined as described by Zhang et al. (2010), matching the results with the MOORE 3.90 library. Respiratory quinones were extracted from freeze-dried cells and purified as described by Tindall (1989). The prepared quinones were analysed using LC-MS (Agilent HC-C 18 , methanol/2-propanol $75: 25$ as the mobile phase at $1.0 \mathrm{ml} \mathrm{min}^{-1}, \lambda=270 \mathrm{~nm}$, column temperature $40{ }^{\circ} \mathrm{C}$; LCQ DECA XP 123 MAX; Thermo Finnigan).

Genomic DNA was extracted as described by Rainey et al. (1996). The DNA G + C content was determined by HPLC, as described by Mesbah et al. (1989), using salmon sperm

Table 1. Differential phenotypic, physiological and genotypic characteristics of strain NS31-3 ${ }^{\top}$ and two members of the genus Parabacteroides

Strains: 1 , Parabacteroides chartae sp. nov. NS31-3 ${ }^{\mathrm{T}} ; 2$, P. merdae JCM $9497^{\mathrm{T}} ; 3$, P. distasonis JCM $5825^{\mathrm{T}}$. Data were taken from this study. All strains were positive for growth on medium containing $20 \%$ bile salts, aesculin hydrolysis, alkaline phosphatase, leucine arylamidase, valine arylamidase, cystine arylamidase, acid phosphatase, naphthol-AS-BI-phosphohydrolase, $\alpha$-galactosidase, $\beta$-galactosidase, $\alpha$-glucosidase, $N$-acetyl- $\beta$-glucosaminidase and acid production from glucose, lactose, sucrose, maltose, xylose, mannose, raffinose and trehalose. All strains were negative for indole production, gelatin hydrolysis, urease, lipase, trypsin and acid production from glycerol. +, Positive; w, weakly positive; -, negative.

\begin{tabular}{|c|c|c|c|}
\hline Characteristic & 1 & 2 & 3 \\
\hline \multicolumn{4}{|l|}{ Temperature for growth $\left({ }^{\circ} \mathrm{C}\right)$} \\
\hline Optimum & $35-37$ & 32 & 37 \\
\hline Range & $10-40$ & $16-45$ & $20-40$ \\
\hline \multicolumn{4}{|l|}{$\mathrm{pH}$ for growth } \\
\hline Optimum & $7.0-7.5$ & 6.9 & 6.0 \\
\hline Range & $5.5-8.5$ & $5.5-8.0$ & $5.5-8.0$ \\
\hline \multicolumn{4}{|l|}{$\mathrm{NaCl}$ for growth $(\%, w / v)$} \\
\hline Optimum & 0 & $0.5-1.0$ & 0.5 \\
\hline Range & $0-2$ & $0-4$ & $0-2$ \\
\hline Catalase & - & - & + \\
\hline \multicolumn{4}{|l|}{ Acid production from: } \\
\hline Arabinose & + & - & - \\
\hline Cellobiose & + & - & + \\
\hline Mannitol & + & - & - \\
\hline Melezitose & + & $+\dagger$ & + \\
\hline Salicin & + & $+\dagger$ & + \\
\hline Sorbitol & + & - & - \\
\hline Rhamnose & - & - & + \\
\hline \multicolumn{4}{|l|}{ Enzymes } \\
\hline Esterase & + & + & $\mathrm{W}$ \\
\hline Esterase lipase & + & + & $\mathrm{w}$ \\
\hline$\alpha$-Chymotrypsin & - & - & + \\
\hline$\beta$-Glucuronidase & - & - & + \\
\hline$\beta$-Glucosidase & + & + & - \\
\hline$\alpha$-Mannosidase & + & - & - \\
\hline$\alpha$-Fucosidase & + & - & - \\
\hline Main fermentation products* & LA, PA, FA, AA & $\mathrm{PP}, \mathrm{SA}, \mathrm{AA}, \mathrm{LA}$ & LA, PA, AA, FA \\
\hline DNA G $+\mathrm{C}$ content $(\mathrm{mol} \%)$ & 37.2 & 41.2 & 42.1 \\
\hline
\end{tabular}

${ }^{\star}$ From PYG broth: AA, acetic acid; FA, formic acid; LA, lactic acid; PA, propionic acid; SA, succinic acid.

$\dagger$ Reported as negative by Sakamoto \& Benno (2006). 
Table 2. Cellular fatty acid compositions of strain NS31-3 and two members of the genus Parabacteroides

Strains: 1 , Parabacteroides chartae sp. nov. NS31-3 ${ }^{\mathrm{T}} ; 2$, P. merdae JCM $9497^{\mathrm{T}}$; 3, P. distasonis JCM $5825^{\mathrm{T}}$. Data were taken from this study.

\begin{tabular}{|lrrr|}
\hline Fatty acids (\%) & $\mathbf{1}$ & $\mathbf{2}$ & $\mathbf{3}$ \\
\hline Saturated straight-chain & & & \\
$\mathrm{C}_{14: 0}$ & 2.9 & 2.0 & 2.9 \\
$\mathrm{C}_{15: 0}$ & 12.7 & 6.6 & 12.5 \\
$\mathrm{C}_{16: 0}$ & 5.1 & 6.3 & 4.7 \\
$\mathrm{C}_{18: 0}$ & 0.4 & 3.2 & 0.8 \\
Unsaturated straight-chain & & & \\
$\mathrm{C}_{16: 1} \omega 9 \mathrm{c}$ & 2.6 & 2.2 & 2.9 \\
$\mathrm{C}_{18: 1} \omega 9 \mathrm{c}$ & 2.5 & 4.7 & 1.8 \\
$\mathrm{C}_{18: 2} \omega 9,12 c$ & 0.5 & 1.0 & 0.6 \\
Hydroxy & & & \\
$\mathrm{C}_{16: 0} 3-\mathrm{OH}$ & 3.8 & 3.7 & 3.6 \\
iso- $\mathrm{C}_{16: 0} 3-\mathrm{OH}$ & 2.0 & 0.7 & 0.4 \\
$\mathrm{C}_{17: 0} 3-\mathrm{OH}$ & 0.7 & 1.0 & 0.5 \\
iso- $\mathrm{C}_{17: 0} 3-\mathrm{OH}$ & 13.1 & 13.7 & 10.7 \\
anteiso-C $17: 0$ 3-OH & 8.2 & 1.0 & 0.6 \\
iso- $\mathrm{C}_{15: 0} \mathrm{ALDE}$ & 1.0 & 1.4 & 1.1 \\
Saturated branched-chain & & & \\
iso- $\mathrm{C}_{13: 0}$ & 1.2 & 1.3 & 1.9 \\
anteiso- $\mathrm{C}_{13: 0}$ & 2.7 & 0.9 & 2.1 \\
iso- $\mathrm{C}_{15: 0}$ & 4.7 & 11.0 & 10.5 \\
anteiso- $\mathrm{C}_{15: 0}$ & 31.1 & 34.4 & 35.9 \\
Summed feature $4{ }^{*}$ & 0.5 & 0.4 & 1.6 \\
& & & \\
\hline
\end{tabular}

*Summed features represent two or three fatty acids that cannot be separated by the Microbial Identification System. Summed feature 4 consisted of equivalent chain-length 12.616 and/or $\mathrm{C}_{15: 1} \omega 7 c$.

DNA as the calibration standard. The $16 \mathrm{~S}$ rRNA gene was amplified using the universal bacterial primers $27 \mathrm{~F}$ and $1492 \mathrm{R}$ and the amplification products were cloned into the vector pMD19-T (TaKaRa) for sequencing (Xu et al., 2007). The 16S rRNA gene sequence was compared with closely related sequences of reference organisms using
FASTA and the EzTaxon service (Chun et al., 2007). Multiple sequence alignment was performed using CLUSTAL W version 1.8 (Thompson et al., 1994). Similarity values were calculated and converted to a distance matrix by the neighbour-joining method (Saitou \& Nei, 1987) using MEGA4 (Tamura et al., 2007). Evolutionary distances were calculated according to the algorithm of Kimura's twoparameter model (Kimura, 1980).

Strain NS31-3 ${ }^{\mathrm{T}}$ was an obligately anaerobic, non-pigmented, non-motile, Gram-negative, short rod (0.7-1.0 × 1.4$2.5 \mu \mathrm{m}$; Fig. S1, available in IJSEM Online). Growth was not inhibited on medium containing $20 \%$ bile salts. Colonies were circular, entire, smooth and off-white-grey $(0.5-1.0 \mathrm{~mm}$ in diameter after $24 \mathrm{~h}$ on medium Gs at $\left.37{ }^{\circ} \mathrm{C}\right)$. Catalase was negative. The isolate grew at $10-40{ }^{\circ} \mathrm{C}$ (optimum $35-37^{\circ} \mathrm{C}$ ), at $\mathrm{pH}$ 5.5-8.5 (optimum $\mathrm{pH}$ 7.07.5 ) and with $0-2 \% \mathrm{NaCl}$ (optimum $0 \%$ ). Phenotypic characteristics are summarized in Table 1 and the species description. Strain NS31-3 ${ }^{\mathrm{T}}$ could be differentiated from reference strains by the ability to ferment mannitol, arabinose and sorbitol (API 20A) and the presence of $\alpha$ mannosidase and $\alpha$-fucosidase (API ZYM). In addition, the isolate differed from $P$. distasonis JCM $5825^{\mathrm{T}}$ by the presence of $\beta$-glucosidase and the absence of $\alpha$-chymotrypsin and $\beta$-glucuronidase.

The major cellular fatty acids of the isolate and the reference strains were anteiso- $\mathrm{C}_{15: 0}$, iso- $\mathrm{C}_{17: 0} 3-\mathrm{OH}$ and $\mathrm{C}_{15: 0}$ (Table 2), although the proportion of anteiso- $\mathrm{C}_{15: 0}$ was slightly lower in strain NS31-3 ${ }^{\mathrm{T}}$. In addition, strain NS31- $3^{\mathrm{T}}$ contained significantly higher proportions of iso$\mathrm{C}_{16: 0} 3-\mathrm{OH}$ and anteiso- $\mathrm{C}_{17: 0} 3-\mathrm{OH}$ and significantly lower proportions of iso- $\mathrm{C}_{15: 0}$. The major menaquinones of the isolate were MK-9 (49.7\%) and MK-10 (44.3\%), and small amounts of MK-7 (0.3\%) and MK-8 (5.7\%) were also present. These major and minor menaquinones were in line with those of $P$. merdae JCM $9497^{\mathrm{T}}$ and $P$. distasonis JCM $5825^{\mathrm{T}}$, although there were some differences in the proportions: 66.8 and $24.3 \%$ for MK-9, 16.2 and

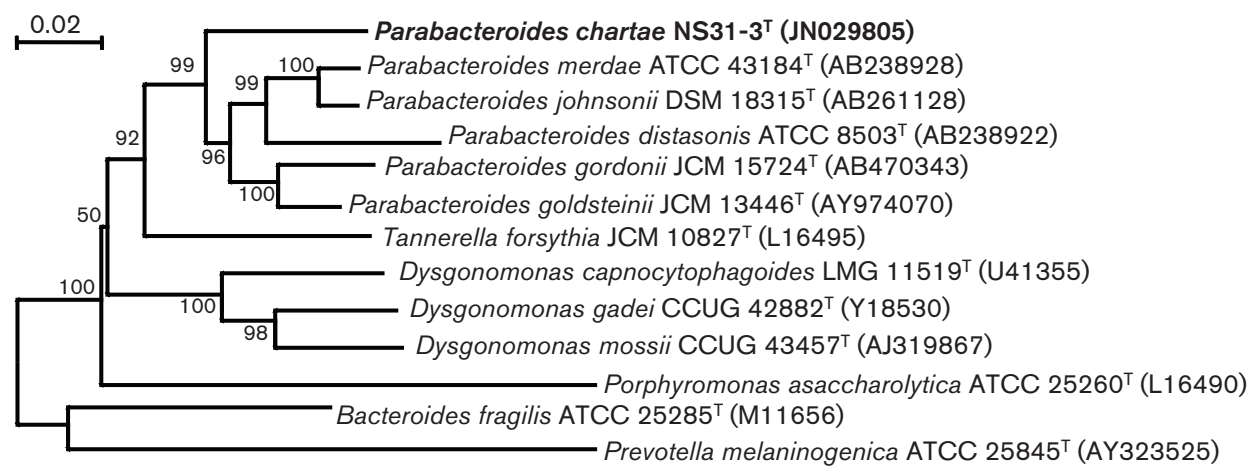

Fig. 1. Neighbour-joining phylogenetic tree based on 16S rRNA gene sequences, showing the phylogenetic relationships of strain NS31-3 ${ }^{\top}$ and related taxa. Bootstrap values $(\geqslant 50 \%)$ based on 1000 replicates are shown at branch nodes. Bar, 0.02 substitutions per nucleotide position. 
$72.7 \%$ for MK-10, 0.3 and $8.9 \%$ for MK-7 and 8.6 and $2.2 \%$ for MK-8, respectively. In general, the menaquinone composition of strain NS31- $3^{\mathrm{T}}$ was consistent with those of members of the genus Parabacteroides (Sakamoto \& Benno, 2006). The genomic DNA G $+C$ content of strain NS31-3 was $37.2 \mathrm{~mol} \%$, which is slightly lower than for P. merdae JCM $9497^{\mathrm{T}}$ and $P$. distasonis JCM $5825^{\mathrm{T}}(41.2$ and $42.1 \mathrm{~mol} \%$, respectively) (Table 1 ).

An almost-complete $16 \mathrm{~S}$ rRNA gene sequence (1481 nt) was obtained from strain NS31-3 ${ }^{\mathrm{T}}$. Phylogenetic analysis indicated that the isolate belonged to a distinct lineage within the cluster containing members of the genus Parabacteroides (Fig. 1). Strain NS31-3 ${ }^{\mathrm{T}}$ exhibited 91.2-93.2\% 16S rRNA gene sequence similarity with the genus Parabacteroides. The isolate's closest neighbour was $P$. merdae JCM $9497^{\mathrm{T}}$.

On the basis of the phenotypic, chemotaxonomic, genotypic and phylogenetic characterization, strain NS31- ${ }^{\mathrm{T}}$ represents a novel species of the genus Parabacteroides, for which the name Parabacteroides chartae sp. nov. is proposed.

\section{Description of Parabacteroides chartae sp. nov.}

Parabacteroides chartae (char'tae. L. gen. n. chartae of/from paper, pertaining to paper milling).

Cells are obligately anaerobic, non-spore-forming, nonpigmented, non-motile, Gram-negative, short rods (0.7$1.0 \times 1.4-2.5 \mu \mathrm{m})$. On medium Gs, colonies are circular, entire, smooth, off-white-grey and $0.5-1.0 \mathrm{~mm}$ in diameter. Grows at $10-40{ }^{\circ} \mathrm{C}$ (optimum $35-37^{\circ} \mathrm{C}$ ), at $\mathrm{pH} 5.5-8.5$ (optimum $\mathrm{pH} 7.0-7.5$ ) and with $0-2 \% \mathrm{NaCl}$ (optimum $0 \%)$. Grows on medium containing $20 \%$ bile salts. Negative for catalase. Indole and urease are not produced. Gelatin and aesculin are hydrolysed. Acid is produced from glucose, lactose, sucrose, maltose, D-xylose, L-arabinose, D-cellobiose, D-mannose, D-melezitose, D-raffinose, D-trehalose, D-mannitol, salicin and D-sorbitol, but not from glycerol or Lrhamnose. With API ZYM, positive for alkaline phosphatase, esterase (C4), esterase lipase (C8), leucine arylamidase, valine arylamidase, cystine arylamidase, acid phosphatase, naphtholAS-BI-phosphohydrolase, $\alpha$-galactosidase, $\beta$-galactosidase, $\alpha$ glucosidase, $\beta$-glucosidase, $N$-acetyl- $\beta$-glucosaminidase, $\alpha$ mannosidase and $\alpha$-fucosidase, but negative for lipase (C14), trypsin, $\alpha$-chymotrypsin and $\beta$-glucuronidase. Mannose and raffinose are fermented. The major end-products from fermentation of PYG broth are lactic acid, propionic acid, formic acid and acetic acid. The major cellular fatty acids are anteiso- $\mathrm{C}_{15: 0}, \mathrm{C}_{15: 0}$ and iso- $\mathrm{C}_{17: 0} 3-\mathrm{OH}$. The predominant respiratory quinones are MK-9 and MK-10.

The type strain, NS31-3 ${ }^{\mathrm{T}}\left(=\mathrm{JCM} 17797^{\mathrm{T}}=\mathrm{DSM} 24967^{\mathrm{T}}\right)$, was isolated from wastewater of a paper mill. The DNA $\mathrm{G}+\mathrm{C}$ content of the type strain is $37.2 \mathrm{~mol} \%$.

\section{Acknowledgements}

This work was supported by the National Natural Science Foundation of China (grant no. 30970002).

\section{References}

Bryant, M. P. (1972). Commentary on the Hungate technique for culture of anaerobic bacteria. Am J Clin Nutr 25, 1324-1328.

Chun, J., Lee, J.-H., Jung, Y., Kim, M., Kim, S., Kim, B. K. \& Lim, Y.-W. (2007). EzTaxon: a web-based tool for the identification of prokaryotes based on 16S ribosomal RNA gene sequences. Int J Syst Evol Microbiol 57, 2259-2261.

Eggerth, A. H. \& Gagnon, B. H. (1933). The bacteroides of human feces. J Bacteriol 25, 389-413.

Gerhardt, P., Murray, R. G. E., Wood, W. A. \& Krieg, N. R. (editors) (1994). Methods for General and Molecular Bacteriology. Washington, DC: American Society for Microbiology.

Hungate, R. E. (1969). A roll tube method for cultivation of strict anaerobes. Methods Microbiol 3B, 117-132.

Johnson, J. L., Moore, W. E. C. \& Moore, L. V. H. (1986). Bacteroides caccae sp. nov., Bacteroides merdae sp. nov., and Bacteroides stercoris sp. nov. isolated from human feces. Int J Syst Bacteriol 36, 499-501.

Kimura, M. (1980). A simple method for estimating evolutionary rates of base substitutions through comparative studies of nucleotide sequences. J Mol Evol 16, 111-120.

Kuykendall, L. D., Roy, M. A., O'Neill, J. J. \& Devine, T. E. (1988). Fatty acids, antibiotic resistance, and deoxyribonucleic acid homology groups of Bradyrhizobium japonicum. Int J Syst Bacteriol 38, 358-361.

Mesbah, M., Premachandran, U. \& Whitman, W. B. (1989). Precise measurement of the $\mathrm{G}+\mathrm{C}$ content of deoxyribonucleic acid by highperformance liquid chromatography. Int J Syst Bacteriol 39, 159-167.

Rainey, F. A., Ward-Rainey, N., Kroppenstedt, R. M. \& Stackebrandt, E. (1996). The genus Nocardiopsis represents a phylogenetically coherent taxon and a distinct actinomycete lineage: proposal of Nocardiopsaceae fam. nov. Int J Syst Bacteriol 46, 1088-1092.

Saitou, N. \& Nei, M. (1987). The neighbor-joining method: a new method for reconstructing phylogenetic trees. Mol Biol Evol 4, 406425.

Sakamoto, M. \& Benno, Y. (2006). Reclassification of Bacteroides distasonis, Bacteroides goldsteinii and Bacteroides merdae as Parabacteroides distasonis gen. nov., comb. nov., Parabacteroides goldsteinii comb. nov. and Parabacteroides merdae comb. nov. Int J Syst Evol Microbiol 56, 1599-1605.

Sakamoto, M., Kitahara, M. \& Benno, Y. (2007). Parabacteroides johnsonii sp. nov., isolated from human faeces. Int J Syst Evol Microbiol 57, 293-296.

Sakamoto, M., Suzuki, N., Matsunaga, N., Koshihara, K., Seki, M., Komiya, H. \& Benno, Y. (2009). Parabacteroides gordonii sp. nov., isolated from human blood cultures. Int J Syst Evol Microbiol 59, 2843-2847.

Shah, H. N. (1992). The genus Bacteroides and related taxa. In The Prokaryotes, 2nd edn, vol. 4, pp. 3593-3607. Edited by A. Balows, H. G. Trüper, M. Dworkin, W. Harder \& K. H. Schleifer. New York: Springer.

Simmon, K. E., Mirrett, S., Reller, L. B. \& Petti, C. A. (2008). Genotypic diversity of anaerobic isolates from bloodstream infections. J Clin Microbiol 46, 1596-1601.

Song, Y., Liu, C., Lee, J., Bolanos, M., Vaisanen, M. L. \& Finegold, S. M. (2005). 'Bacteroides goldsteinii sp. nov.' isolated from clinical specimens of human intestinal origin. J Clin Microbiol 43, 4522-4527.

Tamura, K., Dudley, J., Nei, M. \& Kumar, S. (2007). MEGA4: molecular evolutionary genetics analysis (MEGA) software version 4.0. Mol Biol Evol 24, 1596-1599.

Thompson, J. D., Higgins, D. G. \& Gibson, T. J. (1994). Clustal W: improving the sensitivity of progressive multiple sequence alignment 
through sequence weighting, position-specific gap penalties and weight matrix choice. Nucleic Acids Res 22, 4673-4680.

Tindall, B. J. (1989). Fully saturated menaquinones in the archaebacterium Pyrobaculum islandicum. FEMS Microbiol Lett 60, 251254.

Widdel, F., Kohring, G. W. \& Mayer, F. (1983). Studies on dissimilatory sulfate-reducing bacteria that decompose fatty acids. Arch Microbio $134,286-294$.
Xu, X.-W., Wu, Y.-H., Zhou, Z., Wang, C.-S., Zhou, Y.-G., Zhang, H.-B., Wang, Y. \& Wu, M. (2007). Halomonas saccharevitans sp. nov., Halomonas arcis sp. nov. and Halomonas subterranea sp. nov., halophilic bacteria isolated from hypersaline environments of China. Int J Syst Evol Microbiol 57, 1619-1624.

Zhang, X.-Q., Ying, Y., Ye, Y., Xu, X.-W., Zhu, X.-F. \& Wu, M. (2010). Thermus arciformis sp. nov., a thermophilic species from a geothermal area. Int J Syst Evol Microbiol 60, 834-839. 